Document downloaded from:

http://hdl.handle.net/10251/168605

This paper must be cited as:

Bastida-Molina, P.; Hurtado-Perez, E.; Pérez Navarro, A.; Alfonso-Solar, D. (2021). Light electric vehicle charging strategy for low impact on the grid. Environmental Science and Pollution Research. 28(15):18790-18806. https://doi.org/10.1007/s11356-020-08901-2

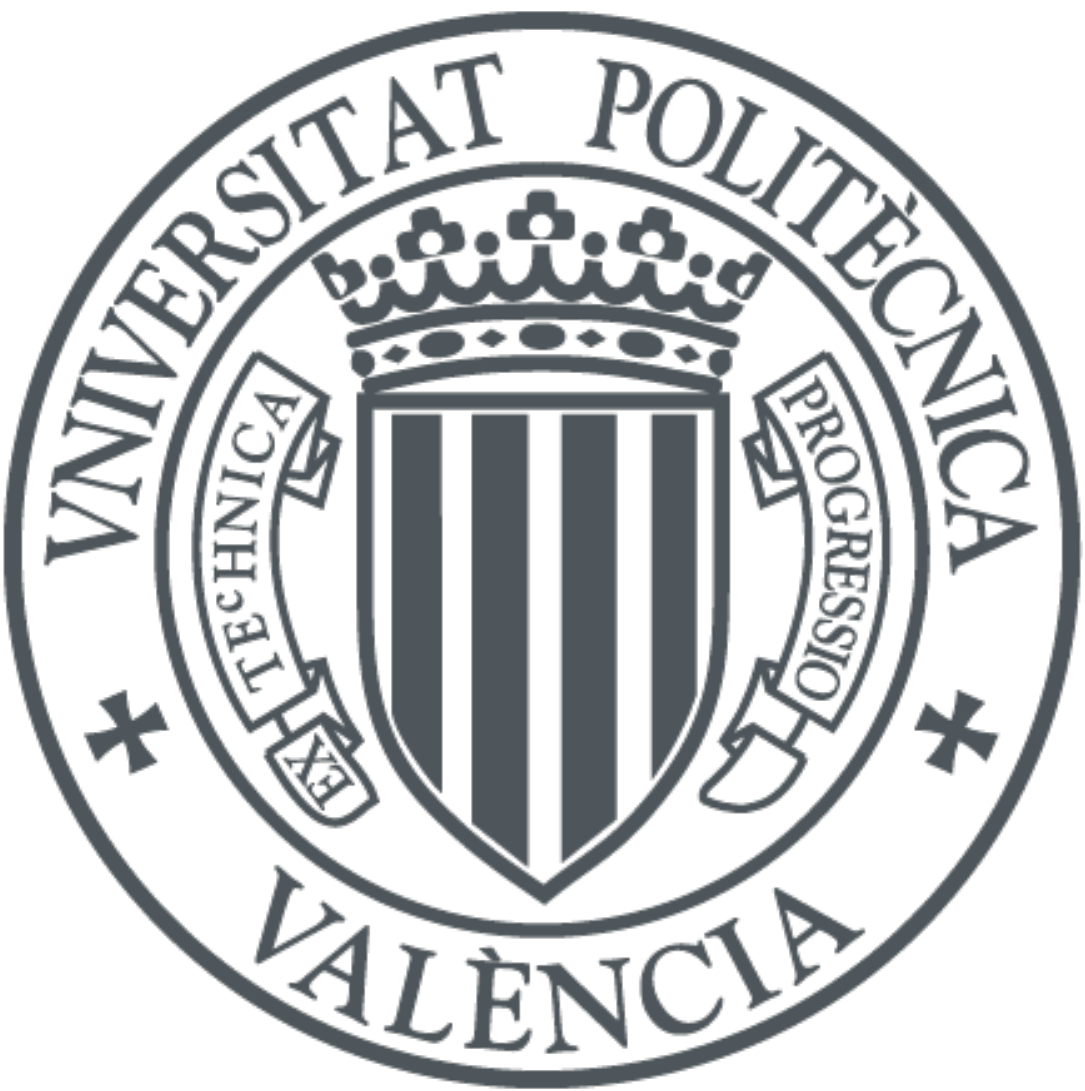

The final publication is available at

https://doi.org/10.1007/s11356-020-08901-2

Copyright Springer-Verlag

Additional Information 


\title{
Light electric vehicle charging strategy for low impact on the grid
}

\author{
Paula Bastida-Molina ${ }^{1 *}$, Elías Hurtado-Pérez ${ }^{2}$, Ángel Pérez-Navarro ${ }^{3}$, David Alfonso-Solar ${ }^{4}$ \\ ${ }^{1}$ Instituto Universitario de Investigación de Ingeniería Energética, Universitat Politècnica de València, \\ Valencia, Spain, paubasmo@etsid.upv.es \\ ${ }^{2}$ Instituto Universitario de Investigación de Ingeniería Energética, Universitat Politècnica de València, \\ Valencia, Spain, ejhurtado@die.upv.es \\ ${ }^{3}$ Instituto Universitario de Investigación de Ingeniería Energética, Universitat Politècnica de València, \\ Valencia, Spain, anavarro@iie.upv.es \\ ${ }^{4}$ Instituto Universitario de Investigación de Ingeniería Energética, Universitat Politècnica de València, \\ Valencia, Spain, daalso@iie.upv.es
}

\begin{abstract}
The alarming increase in the average temperature of the planet due to the massive emission of greenhouse gases has stimulated the introduction of electric vehicles (EV), given transport sector is responsible for more than $25 \%$ of the total global $\mathrm{CO}_{2}$ emissions. EV penetration will substantially increase electricity demand and, therefore, an optimization of the EV recharging scenario is needed to make full use of the existing electricity generation system without upgrading requirements. In this paper, a methodology based on the use of the temporal valleys in the daily electricity demand is developed for EV recharge, avoiding the peak demand hours to minimize the impact on the grid. The methodology assumes three different strategies for the recharge activities: home, public buildings and electrical stations. It has been applied to the case of Spain in the year 2030, assuming three different scenarios for the growth of the total fleet: low, medium and high. For each of them, three different levels for the EV penetration by the year 2030 are considered: $25 \%, 50 \%$ and $75 \%$, respectively. Only light electric vehicles (LEV), cars and motorcycles, are taken into account given the fact that batteries are not yet able to provide the full autonomy desired by heavy vehicles. Moreover, heavy vehicles have different travel uses that should be separately considered. Results for the fraction of the total recharge to be made in each of the different recharge modes are deduced with indication of the time intervals to be used in each of them. For the higher penetration scenario, $75 \%$ of the total park, an almost flat electricity demand curve is obtained. Studies are made for working days and for non-working days.
\end{abstract}

\section{Keywords}

Electric vehicle, recharging strategy, schedule optimization, demand curve, temporal valleys, peak loads. 


\section{Introduction}

During the last years, climate change has become one of the most worrisome problems. The huge quantity of greenhouse gases emitted to the atmosphere is leading to a dangerous temperature increase, whose negative effects are duly documented (Akitt, 2018).

Transport sector, with almost a quarter of the total carbon dioxide emissions, is one of the most polluting sectors (Bjerkan, Nørbech and Nordtømme, 2016; Teixeira and Sodré, 2018; Hasan et al., 2019). Besides, transport depends mostly on fossil fuels whose reserves are finite and could be exhausted in a short or medium term. Both phenomena, environmental impact and finite reserves, have motivated the electrification of the transport sector (Dijk, Orsato and Kemp, 2013; Adnan et al., 2017). The balance between the $\mathrm{CO}_{2}$ emissions due to the generation of a surplus of electricity to supply EV and the emissions avoided by the use of these EV could be highly favorable (Canals Casals et al., 2016; Morrissey, Weldon and O'Mahony, 2016), making EV an environmental solution for transport. Therefore, a high penetration of $\mathrm{EV}$ in the transport sector is taking place.

The electrical behavior of this kind of vehicles lies in both their electrical charge depleting and recharging electrical demand, which are hugely affected by the EV driving cycle and the state of the battery. Regarding the EV driving cycle, the study (Zhao, Ma, et al., 2018) develops a methodology to construct an EV urban driving cycle for analyzing the differences in estimated EV energy consumption. It is based on the general topological structure of the studied urban roads and their traffic flow. Authors apply the methodology to the city of Xi'an as a case of study. Finally, the application of the developed driving cycle together with other international driving cycles to the city revealed that when the latter are used, energy consumption errors increase up to $21.17 \%$. The research (Zhao, Yu, et al., 2018) goes a step further and proposes a methodology based on a k-means and a support vector machines hybrid clustering algorithm to select the most representative EV urban driving cycle. The application of the methodology to Xi'an EV urban driving cycle effectively matches the speed-time driving pattern of the real-world cycle, proving therefore the feasibility of the method. Referring to the state of batteries, Zhang et al (Zhang et al., 2019) focus their study on the accurate estimation of the State of Charge (SOC) of lithium-ion batteries, which are widely used for energy storage in EV. Their novel methodology allows for an optimization of the noise information by means of an "ant-lion" optimizer algorithm. Results verify the suitable noise optimization making use of the developed algorithm, so that SOC of batteries could be accurately estimated with error ratios lower than $1 \%$. Another research (Wang, Wei and Dai, 2019) develops a diagnosis of the state of health of lithium-ion batteries based on charge transfer resistance and taking different temperature and SOC parameters as inputs. The study leads to a battery state of health estimation method that eliminates the need of controlling the temperate and $\mathrm{SOC}$ of batteries during the measurement.

After the analyses of EV electrical behavior, different studies (Ahmadi et al., 2012; Deb et al., 2018; Galiveeti, Goswami and Dev Choudhury, 2018; Gong et al., 2018) claim that a massive introduction of EV would create negative impacts on the grid, leading to new power network challenges (Clairand, Rodríguez-García and Álvarez-Bel, 2018). With this problem in mind, several studies have lately proposed different solutions to minimize the impact of EV on the grid (Wang and Chen, 2019). 
One study has focused on the reshape of electricity load demand from EV recharge in the case of a high expected introduction of EV (López et al., 2015). The study for EV penetration in New Zealand (Su, Lie and Zamora, 2019) shows how the EV demand would increase each year with the consumption concentrated in peak hours, particularly at the end of the day. Under these circumstances, peak loads increase until arriving to a critical point in 2040 when the highest peak demand would exceed 2018 New Zealand installed generation capacity. Other studies, applied to Brazil (Baran and Legey, 2013) and to the European Nordic Region (Liu et al., 2014), reach the same conclusion: the electricity demand due to the introduction of EV would substantially increase peak loads, with the corresponding negative impacts on the electricity network and the installed capacity of those regions.

EV recharging processes tend to have a random behavior (Ortega-Vazquez, Bouffard and Silva, 2013; Dang, 2018; Mao, Gao and Wang, 2019) when compared to traditional electricity load profiles, but no limitations measures have been yet applied to control those recharging processes due to the recent appearance of EV in transportation. Nowadays, users freely choose the charging time to recharge their batteries, so the process schedule is a self-personalized one (Dang and Huo, 2018). This uncontrolled situation is the responsible for an overlapping between EV charging loads with the grid peak loads that could increase the requirements at the peak periods. Therefore, scheduling the different recharging options is completely necessary to avoid peak demand increases with the consequent grid problems (Sundstrom and Binding, 2012).

Although several studies have analyzed the impact of EV introduction in the grid, just only a few have based their investigation on scheduling the recharge activities. One of this is the above mentioned in New Zealand (Su, Lie and Zamora, 2019), based on time restrictions to be applied to private and utility EV and electric buses. Following these constraints, The European Nordic Region study (Liu et al., 2014) considers also a timed charging strategy based on the spot price, but this method is applied only for EV passenger cars. Reschedule of the charging processes based on dynamic pricing is studied and applied to a case of study in Germany (Limmer and Rodemann, 2019).

None of these studies consider real drivers recharging patterns, that should be the basis for real recharging strategies, and can be included in three different categories: recharge at home, electrical stations or public buildings (IDAE, 2012; Martínez-Lao et al., 2017; REE, 2018; Wang and Infield, 2018; Danté et al., 2019). The aim of this paper is to deduce an optimization methodology to avoid peak demand hours by the introduction of EV. This methodology is based on the use of electricity demand temporal valleys and provides an optimization of the distribution of recharge between the three different recharge options.

The methodology considers only the contribution of light electric vehicles (LEV) by including cars and motorcycles. Main reason for this limitation lies in the different recharging behavior and travel use of heavy vehicles, like trucks or buses. Furthermore, the currently available batteries are not yet able to provide the full autonomy desired for heavy vehicles.

This methodology has been applied to the case of Spain in the year 2030, assuming three different scenarios for the growth of the total fleet: low, medium and high. For each of them, three different levels for the LEV penetration are considered: $25 \%, 50 \%$ and $75 \%$, respectively. Spain is one of the countries where a large-scale introduction of LEV is expected to happen in the near future. This is because the recent Climate Change and Energy Transition draft proposed by the Spanish 
Government (PNIEC, 2019) forbids by 2040 the registration and sale of any light vehicle which emits $\mathrm{CO}_{2}$. Some previous studies have addressed the effect of EV on the grid for this country or some of their regions. For instance, in (Ceballos Delgado, Caicedo Bravo and Ospina Arango, 2016) the impact of EV on the distribution network is analyzed for Spain, Chile and Colombia. The impact of charging EV on the distribution grid of a region in Spain (Barcelona) is detailed in (Valsera-Naranjo et al., 2012) with emphasis on the importance of mobility variables when studying this impact. Despite the importance of all these studies, a scheduling of the EV charging has not been yet studied. This research gap and the forecasted high introduction of LEV in Spanish society, make 2030 Spain case study a certainly suitable one to prove the feasibility of the suggested methodology.

This paper is organized as follows: the developed methodology is described in section 2; the case of study with the application to Spain in the year 2030 with different degrees of LEV penetration including results and discussion is presented in section 3; finally, some general conclusions are presented in section 4 .

\section{Methodology}

In this section, a LEV recharging strategies optimization methodology is presented. This methodology is based on the reschedule of LEV recharge using temporal valleys in the electricity demand curve and its distribution between the different options for recharging. A brief overview of the methodology is shown on the flowchart at the Figure 1.

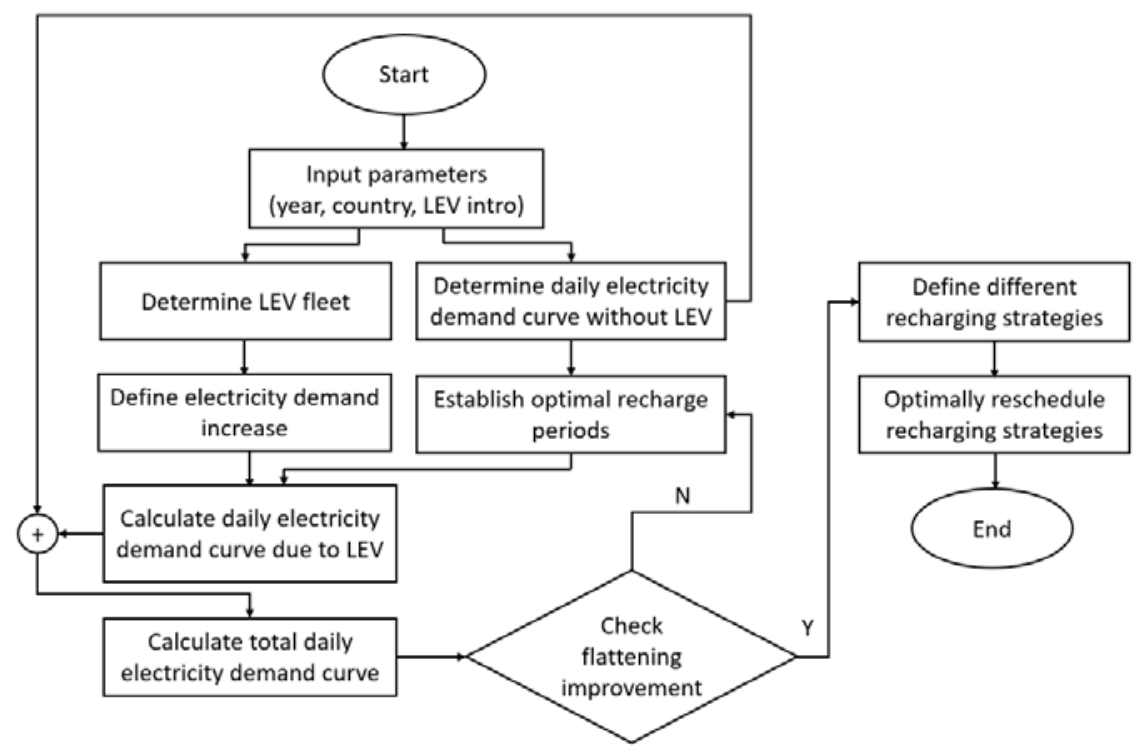

Figure 1. Flowchart of the proposed methodology.

The recharge approach starts with the determination of the expected LEV fleet using data from different official sources and its extrapolation to the year under consideration. The electricity demand from the calculated LEV fleet is determined and distributed along the optimal recharging periods deduced from the valleys in the total electricity daily demand curve. By adding this total electricity demand to the LEV demand, a final daily demand curve is obtained and its possible flattening is 
analyzed to check how much the initial demand curve has been affected. Once an adequate flattening is obtained, the distribution of the total LEV electricity demand between the different recharging methods (home, electrical stations and public buildings) is optimized.

\subsection{LEV fleet}

During these last years, almost every developed country has experimented a large-scale introduction of LEV (Baran and Legey, 2013; Canals Casals et al., 2016; REE, 2018). This trend is ever increasing now, so that forecasting LEV fleet in a long term becomes a difficult data to obtain, but critical for the determination of the impact on the electrical grid.

To determine the LEV fleet, the methodology considers four different vehicle types (Al-Alawi and Bradley, 2013; Martínez-Lao et al., 2017): pure electric cars (PEC), hybrid electric cars (HEC), pure electric motorcycles (PEM) and hybrid electric motorcycles (HEM). From the extrapolation of the historical data (DGT, 2017) for light combustion cars (LCC) and motorcycles (LCM), and the assumption of penetration factors for each of the different considered LEV, the total LEV fleet $\left(\mathrm{N}_{T}\right)$ is deduced for the particular year under consideration:

$$
\mathrm{N}_{\mathrm{T}}=\sum_{\mathrm{i}=1}^{4} \mathrm{~N}_{\mathrm{i}}=\left[\mathrm{f}_{\mathrm{LCC}}\left(\mathrm{t}_{0}\right) \cdot \sum_{\mathrm{i}=1}^{2} \mathrm{p}_{\mathrm{i}}\left(\mathrm{t}_{0}\right)\right]+\left[\mathrm{f}_{\mathrm{LCM}}\left(\mathrm{t}_{0}\right) \cdot \sum_{\mathrm{i}=3}^{4} \mathrm{p}_{\mathrm{i}}\left(\mathrm{t}_{0}\right)\right]
$$

where: $\mathrm{N}_{\mathrm{i}}$ represents the fleet for the different types of LEV $\mathrm{i}(\mathrm{i}=1$ (PEC); $\mathrm{i}=2$ (HEC); $\mathrm{i}=3$ (PEM) and $\mathrm{i}=4$ $(H E M)) ; f_{L C C}\left(t_{0}\right)$ and $f_{L C M}\left(t_{0}\right)$ are the extrapolated values in the year $t_{0}$ of the different LCC and LCM, respectively, and $p_{i}$ is the penetration factor of the different types of electric vehicles $i$.

Hence, the nature (cars/motorcycles) of the introduced LEV matches the nature of the LCV replaced. Therefore, the introduction of electric cars (PEV and HEV) would influence LCC, whereas electric motorcycles (PEM and HEM) would affect LCM.

\subsection{Electricity demand increase}

The electricity demand from the total LEV fleet will be given by:

$$
\Delta_{\mathrm{ED}}=\sum_{1}^{4}\left(\mathrm{C}_{\mathrm{a}} \cdot \mathrm{f}_{\mathrm{h}} \cdot \overline{\mathrm{d}}_{\mathrm{a}}\right)_{\mathrm{i}} \cdot \mathrm{N}_{\mathrm{i}}
$$

where the electrical consumption of each type of electric vehicle is affected by three factors: the average certified electrical consumption $\left(C_{a}\right)$; a real increase consumption factor $\left(f_{h}\right)$ over those certified values, and the average annual travel distance $\left(\overline{\mathrm{d}}_{\mathrm{a}}\right)$.

Values for all these parameters are summarized in Table 1. $\mathrm{C}_{\mathrm{a}}$ can be obtained from the review of the certified consumption for a large quantity of existing and planned LEV models (Luca de Tena and Pregger, 2018). However, different studies (Tietge, Díaz, et al., 2016; Tietge, Mock, et al., 2016; Zhao, Ma, et al., 2018) claim that those average certified consumption values differ from the real ones, since values obtained under the tested conditions are lower than those obtained under real road conditions due to the low demanding conditions of the former tests. Factor $f_{h}$ is deduced by using extrapolated 
data from (Tietge, Mock, et al., 2016). Averaged annual traveling distances, $\bar{d}_{a}$, could be deduced from (INE, 2018).

Table 1. LEV electrical consumption parameters

\begin{tabular}{lccc}
\hline & $\begin{array}{c}\mathrm{C}_{\mathrm{a}} \\
(\mathrm{kWh} / 100 \mathrm{~km})\end{array}$ & $\mathrm{f}_{\mathrm{h}}$ & $\begin{array}{c}\overline{\mathrm{d}}_{\mathrm{a}} \\
(\mathrm{km} / \mathrm{year})\end{array}$ \\
\hline PEC & 13.7 & 1.67 & 12563 \\
HEC & 4.6 & 1.67 & 12563 \\
PEM & 6.3 & 1.67 & 6302 \\
HEM & 2.1 & 1.67 & 6302 \\
\hline
\end{tabular}

\subsection{Total daily electricity demand curve}

To deduce the total daily electricity demand curve, we should add to the demand from the different sectors (industry, residential, commercial and services, agriculture and fishing), the demand due to the LEV recharge. This sectorial demand curve can be calculated by assuming that its shape is unchanged in the future and only a multiplying factor for the entire profile, due to the increase in demand, should be applied. This factor $\left(M_{f}\right)$ is given by eq. 3

$$
M_{f}=\frac{E_{y}}{E_{y_{0}}}
$$

where $E_{y}$ corresponds to the total forecasted electricity demand for the year into consideration and $\mathrm{E}_{\mathrm{y}_{0}}$ to the electricity demand for the current year.

Historical data from official sources contain information about the electricity consumed in each country along the years. For instance, in the case of Spain, (REE, 2017b) contains national electricity consumption data from 1990 to our days, with the possibility of different period visualizations (diary, monthly, yearly) or locations selection (regions, peninsula, national). Therefore, $\mathrm{E}_{\mathrm{y}_{0}}$ is directly obtained from the historical data of the country in question, whereas $\mathrm{E}_{\mathrm{y}}$ corresponds to a lineal extrapolation of them to the year under study.

Besides, load users' patterns present considerable differences between working and nonworking days (REE, 2017a), so two different predicted daily demand curves should be determined in the methodology application.

Once the sectorial demand profiles are deduced, the distribution along the day of the electricity demanded by the LEV is made in accordance with a distribution function deduced from those profiles. This distribution function $(P(t))$ is given by:

$$
P(t)=\left(D_{0}(t)-\widehat{D_{0}}\right) / \int_{0}^{24}\left(D_{0}(t)-\widehat{D}_{0}\right) \cdot d t
$$

where $\mathrm{D}_{0}(t)$ is the sectorial daily demand profile for the considered year and $\widehat{\mathrm{D}}_{0}$ is the maximum value on that profile. 
Typical total sectorial electricity demand profiles for working and non-working days are presented in figure 2, together with the corresponding distribution function for the LEV electricity demand deduced using eq.4.

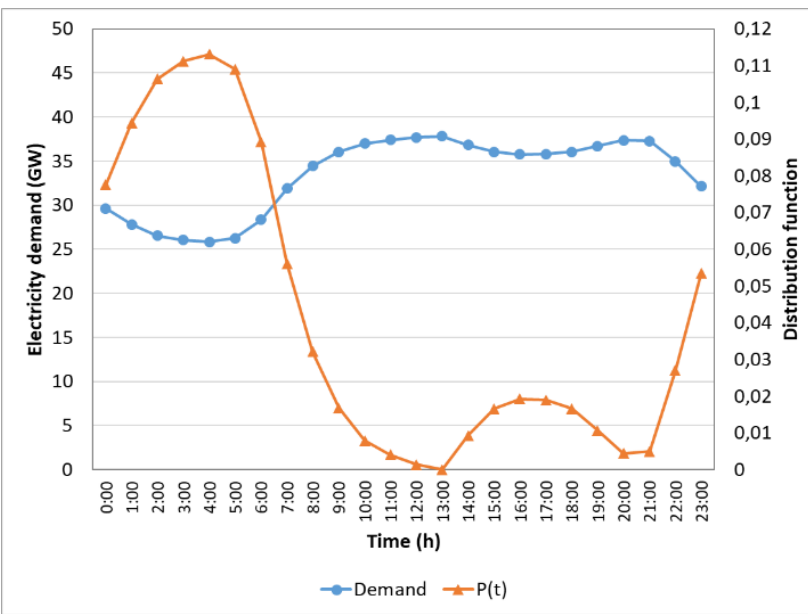

(a)

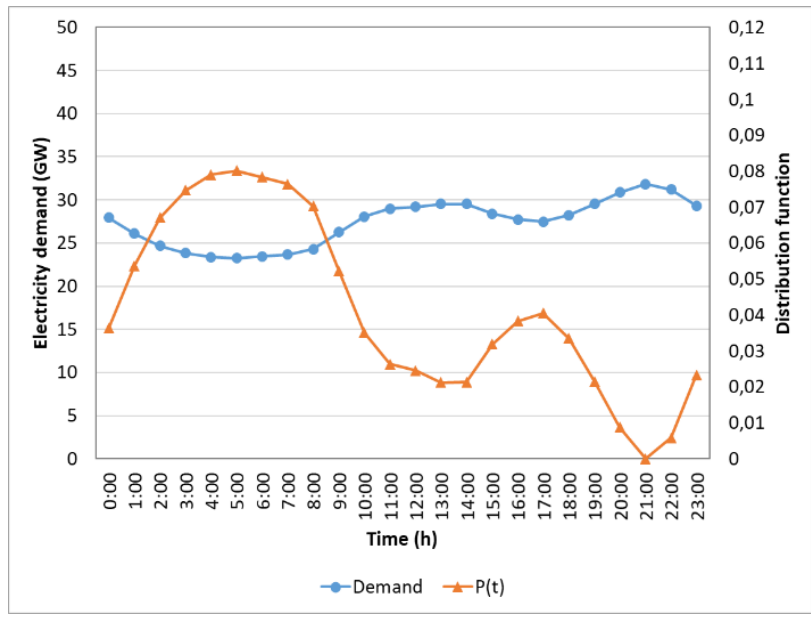

(b)

Figure 2. Sectorial demand profile and deduced LEV recharge distribution functions for working (a) and non-working (b) days

The distribution of the LEV electricity demand along the day is deduced by using this distribution function.

$$
D_{\mathrm{LEV}}(\mathrm{t})=\Delta_{\mathrm{ED}} \cdot \mathrm{P}(\mathrm{t})
$$

Therefore, the total electricity demand profile will be given by:

$$
D_{T}(t)=D_{L E V}(t)+D_{0}(t)
$$

Using this approach, the total daily electricity demand curve is expected to be a flatter one. To verify this effect, a flat factor $F_{f}$ is calculated as:

$$
\mathrm{F}_{\mathrm{f}}=\frac{1}{24} \cdot \int_{0}^{24} \frac{\mathrm{D}_{\mathrm{T}}(\mathrm{t})}{\widehat{\mathrm{D}}_{\mathrm{T}}} \cdot \mathrm{dt}
$$

Figure 3 displays the application of this methodology to the distribution of the demand of electricity from LEV, assuming this demand as a $50 \%$ of the total one. There is a clear improvement in the flattening of the profile, without any increase in the peak demand value, by displacing the LEV charge to the valleys in the demand curve. 


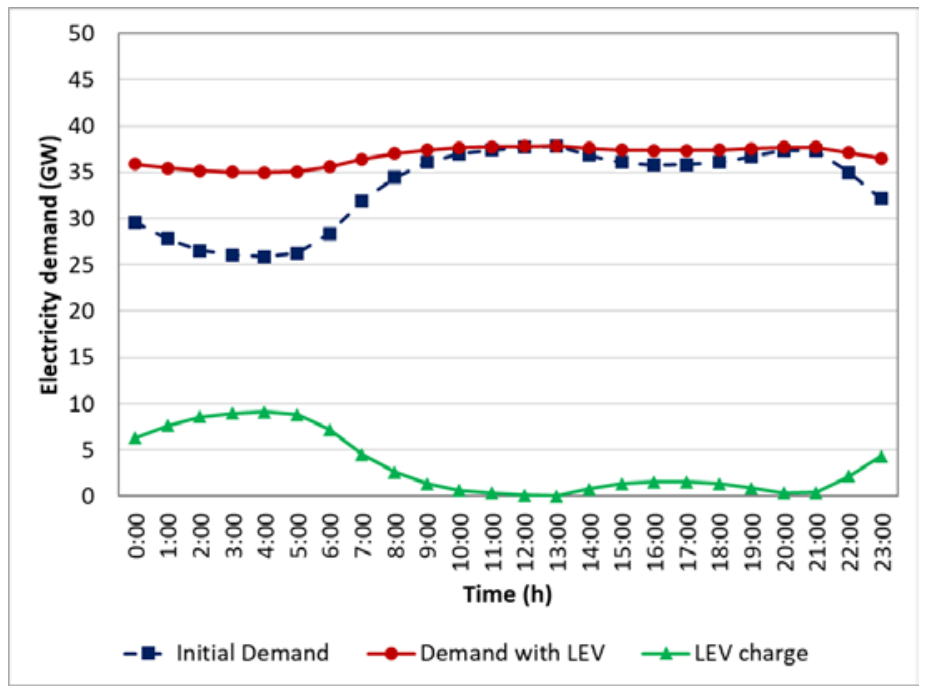

Figure 3. Demand curve flattening

\subsection{LEV recharging strategies}

An optimal distribution of the LEV electricity demand could be obtained using the abovedescribed methodology. However, another barrier needs to be considered regarding the different recharging strategies for LEV (Liu et al., 2014; Dang, 2018; Desai, Chen and Armington, 2018; Su, Lie and Zamora, 2019). These strategies would consider the recharging behavior of the users, which basically are: recharging at home, electrical stations or public buildings (IDAE, 2012; Martínez-Lao et al., 2017; REE, 2018; Wang and Infield, 2018; Danté et al., 2019) and should optimize the distribution of the required demand between these options.

\subsubsection{Recharge at home}

This type of recharging mode corresponds to the users who would recharge LEV in their garages while they are at home. Hence, recharging hours are related to working schedules of citizens. During working days, most of the citizens using this option would connect their LEV as soon as they arrive home from their work and would disconnect them next morning before going back to work. During non-working days, the most remarkable period of recharging would still be night hours. However, daily hours would experiment an increase, since some people stay at home on these days.

According to (IDAE, 2012; Martínez-Lao et al., 2017; REE, 2018), given the high number of available hours for recharge, this strategy corresponds to a slow mode of recharging. Hence, the recharger unit to supply a complete charge in about 8 hours could be based in a system with a maximum intensity of $16 \mathrm{~A}$ at $230 \mathrm{~V}$.

\subsubsection{Recharge at electrical stations}

Recharging at electrical stations involves users who would specifically stop in a public point because they want the LEV batteries quickly be recharged, so that they can continue with the trip. 
Electrical stations would be equivalent to current petrol stations (Alhazmi, Mostafa and Salama, 2017; Bagher Sadati et al., 2019) with a quick recharging mode (IDAE, 2012; Martínez-Lao et al., 2017; REE, 2018). Hence, the charge duration should be about 30-45 minutes, and the recharger should be able to supply around $400 \mathrm{~A}$ at $400 \mathrm{~V}$.

\subsubsection{Recharge in public buildings}

Refilling LEV batteries in public buildings like parking, supermarkets, shopping centers, etc., during the periods owners are developing other activities corresponds to this type of recharge. This strategy corresponds to an semi-quick mode of recharging (IDAE, 2012; Martínez-Lao et al., 2017; REE, 2018) with a standard charge duration of about 2 hours, and the recharger should supply 64 A at 400 V.

An adequate splitting between these three recharging options should cover the obtained distribution of the total LEV electricity demand, as eq. 8 indicates.

$$
D_{\text {LEV }}(t)=H(t)+E(t)+P(t)
$$

Being $H(t), E(t)$ and $P(t)$ the contributions to the demand from home, electrical stations and public buildings, respectively. Each of these contributions depend on their daily recharging probability profiles, as eq. 9 to 11 indicate.

$$
\begin{aligned}
& H(t)=D_{L E V}(t) \cdot p_{h}(t) \\
& E(t)=D_{L E V}(t) \cdot p_{e}(t) \\
& P(t)=D_{L E V}(t) \cdot p_{p}(t)
\end{aligned}
$$

where $\mathrm{p}_{\mathrm{h}}(\mathrm{t}), \mathrm{p}_{\mathrm{e}}(\mathrm{t})$ and $\mathrm{p}_{\mathrm{p}}(\mathrm{t})$ are the daily recharging probability profiles for home, electrical stations and public buildings, respectively.

For each case, these parameters arise as proportional contributions to the daily pattern for each recharging option, as eq. 12 to 14 show.

$$
\begin{aligned}
& p_{h}(t)=\frac{h(t)}{h(t)+e(t)+p(t)} \\
& p_{e}(t)=\frac{e(t)}{h(t)+e(t)+p(t)} \\
& p_{p}(t)=\frac{p(t)}{h(t)+e(t)+p(t)}
\end{aligned}
$$


where $\mathrm{h}(\mathrm{t}), \mathrm{e}(\mathrm{t})$ and $\mathrm{p}(\mathrm{t})$ represent the daily patterns for home, electrical stations and public buildings strategies, respectively. These patterns would match not only the typical recharging schedule from each strategy (section 2.4.1, 2.4.2 and 2.4.3) but also the way of life of users for the specific region under consideration, to deduce from each country official data.

\section{Case of study: Spain in $\mathbf{2 0 3 0}$}

As an application of the developed methodology for the optimization of the impact on the grid due to the penetration of the LEV, this study has been addressed for the case of Spain in the year 2030. In 2018, there were 25.500 electric cars and 12.350 electric motorcycles (REE, 2018), which represented just a $1 \%$ of the total Spanish light transport fleet. Despite this small presence, the introduction of LEV in Spain has experimented a big growth in the last few years and even a bigger increase is forecasted for the medium term. In this study, we are assuming three different scenarios for the growth of the total LCV fleet: low, medium and high, as detailed at figure 4. For each of them, three different levels for the LEV penetration by the year 2030 are considered: $25 \%, 50 \%$ and $75 \%$, respectively.

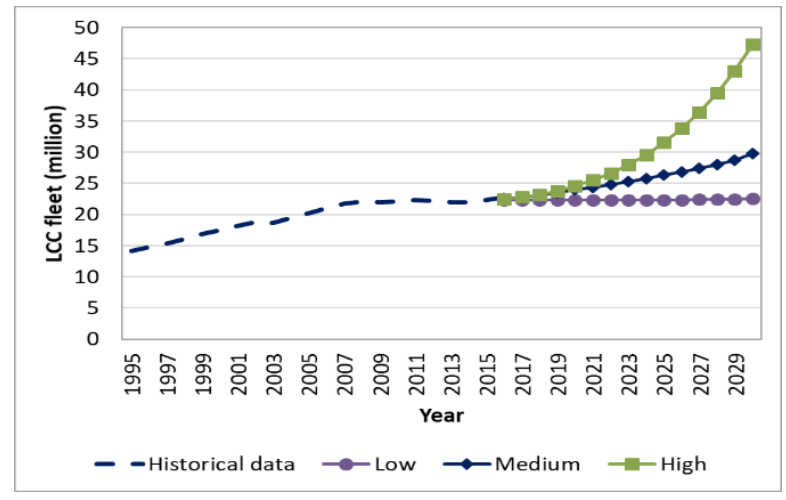

(a)

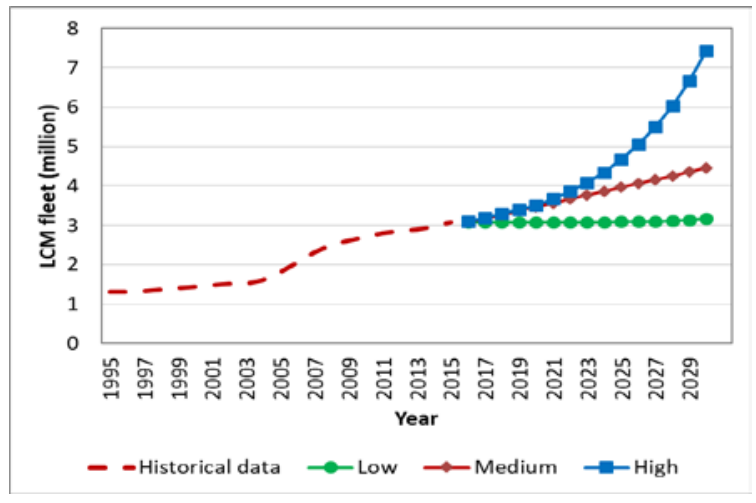

(b)

Figure 4. Scenarios for the growth of LCV in Spain. (a) LCC. (b) LCM.

\subsection{LEV fleet}

Following the methodology proposed in this paper, we can deduce the total number of electric cars and motorcycles by applying an increasing factor to the values deduced from the extrapolation to the year 2030 of the historical data available for LCV in Spain (DGT, 2017). Table 2 shows the LEV fleet composition for the different penetration levels in each of the assumed scenarios with the assumption of an equal distribution between pure electric and hybrid vehicles. 
Table 2. LEV fleet composition for the different scenarios

\begin{tabular}{cccccc|}
\hline \multicolumn{5}{c}{ Number of vehicles (millions) } \\
\hline \multirow{3}{*}{ Scenario } & $\begin{array}{c}\text { LEV fraction } \\
\text { (\%) }\end{array}$ & PEC & HEC & PEM & HEM \\
& 25 & 2,8 & 2,8 & 0,4 & 0,4 \\
& 50 & 5,6 & 5,6 & 0,8 & 0,8 \\
& 75 & 8,4 & 8,4 & 1,2 & 1,2 \\
\hline \multirow{3}{*}{ Medium } & 25 & 3,7 & 3,7 & 0,6 & 0,6 \\
& 50 & 7,4 & 7,4 & 1,2 & 1,2 \\
& 75 & 11,2 & 11,2 & 1,7 & 1,7 \\
\hline \multirow{3}{*}{ High } & 25 & 5,9 & 5,9 & 0,9 & 0,9 \\
& 50 & 11,8 & 11,8 & 1,9 & 1,9 \\
& 75 & 17,7 & 17,7 & 2,8 & 2,8 \\
\hline
\end{tabular}

\subsection{Electricity demand increase}

If no LEV were introduced in Spain, the total sectorial electricity demand in the year 2030 would be around $279 \mathrm{TWh}$, deduced from a lineal extrapolation to that year of the electricity consumption in Spain during the period 2013-2017 (REE, 2017b). This represents an increase of 10,3\% in relation to the last available data for 2017.

The increases in electricity demand due to the LEV introduction are calculated by using eq. 2 with values from the table 1 . Results for the different penetration levels in each of the assumed fleet scenario are summarized in table 3 and figure 5.

Table 3. LEV Electricity demand

\begin{tabular}{ccccc}
\hline \multicolumn{5}{c}{ LEV electricity demand } \\
\hline \multirow{2}{*}{ Scenario } & $\begin{array}{c}\text { LEV fraction } \\
(\%)\end{array}$ & $\begin{array}{c}\text { Annual } \\
(\text { TWh })\end{array}$ & $\begin{array}{c}\text { Daily } \\
(\text { GWh })\end{array}$ & $\begin{array}{c}\text { Increase } \\
(\%)\end{array}$ \\
\hline \multirow{4}{*}{ Low } & 25 & 11,1 & 30,5 & 4,0 \\
& 50 & 22,2 & 60,9 & 8,0 \\
& 75 & 33,4 & 91,4 & 12,0 \\
\hline \multirow{3}{*}{ Medium } & 25 & 14,7 & 40,3 & 5,3 \\
& 50 & 29,4 & 80,7 & 10,6 \\
& 75 & 44,2 & 121,0 & 15,8 \\
\hline \multirow{3}{*}{ High } & 25 & 23,5 & 64,3 & 8,4 \\
& 50 & 46,9 & 128,5 & 16,8 \\
& 75 & 70,4 & 192,8 & 25,2 \\
\hline
\end{tabular}




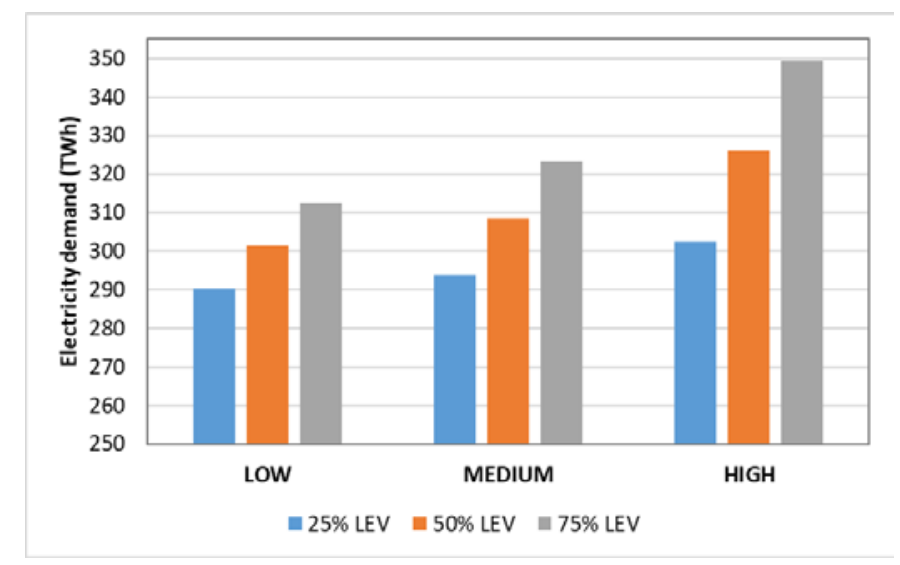

Figure 5. Total electricity demand

A maximum increase of $25,2 \%$ is obtained for the most demanding scenario: $75 \%$ LEV penetration for a high growth of the total light vehicle fleet.

\subsection{Total daily electricity demand curves}

Nowadays, current load patterns for electricity users present considerable differences between working and non-working days (REE, 2017a). Therefore, two different predicted 2030 Spanish daily demand curves have been used in this study. If these demand profiles are the same all along the year, we can distribute the total electricity LEV consumptions between working and non-working days, by considering the total number of days for each type along the entire year. The profile for the deduced daily electricity demand in each case is deduced by applying the probability distribution function of eq.4.

Assuming for the year 2030 the conservation of the sectorial electricity demand curve shape existing at 2017 (REE, 2017a), we can upgraded it by application of the multiplication factor of the total demand deduced in paragraph 3.2. By adding the two demand profiles: sectorial and LEV demand ones, we obtain the total daily demand profile, both for working and non-working days. Figures 6 to 8 display those demand curves for the three scenarios under consideration. 


\section{LEV penetration $=25 \%$}

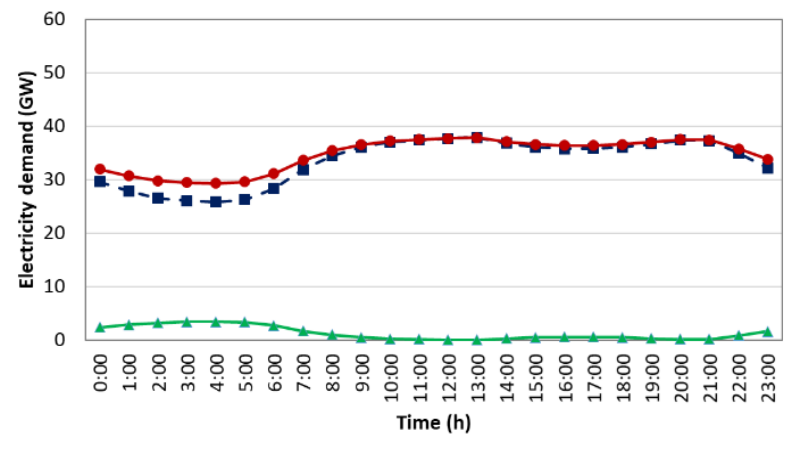

- Initial Demand $\rightarrow$ Demand with LEV $\rightarrow$ LEV charge

LEV penetration $=50 \%$

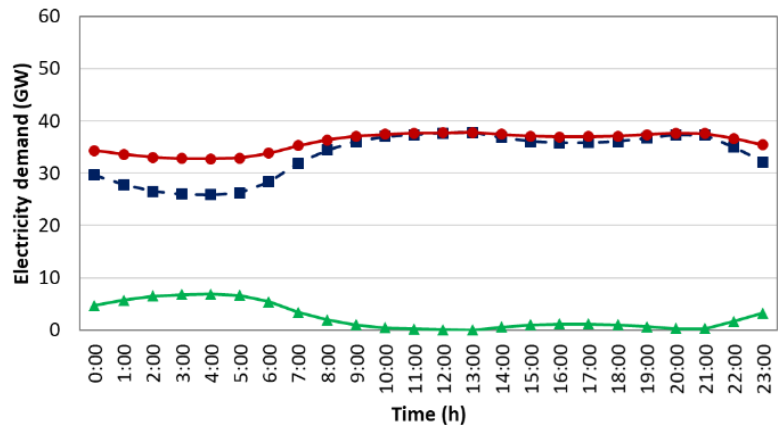

- Initial Demand $\rightarrow$ Demand with LEV $\rightarrow$ LEV charge

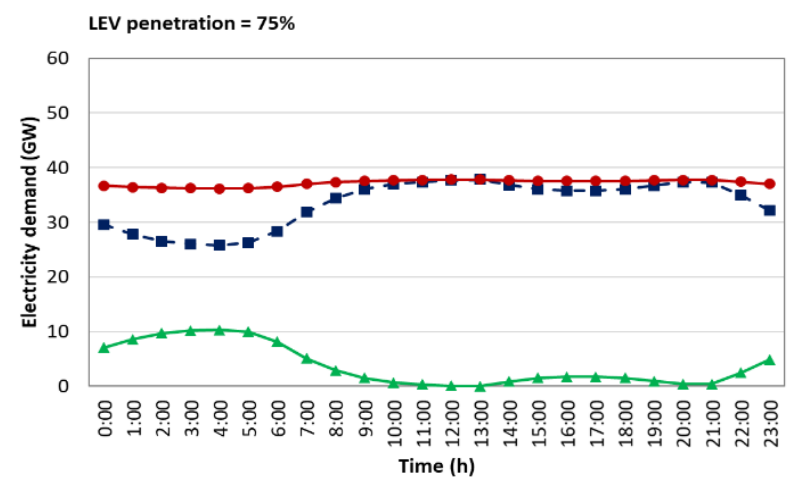

- Initial Demand $\rightarrow$ Demand with LEV $\rightarrow$ LEV charge

(a)
LEV penetration $=25 \%$

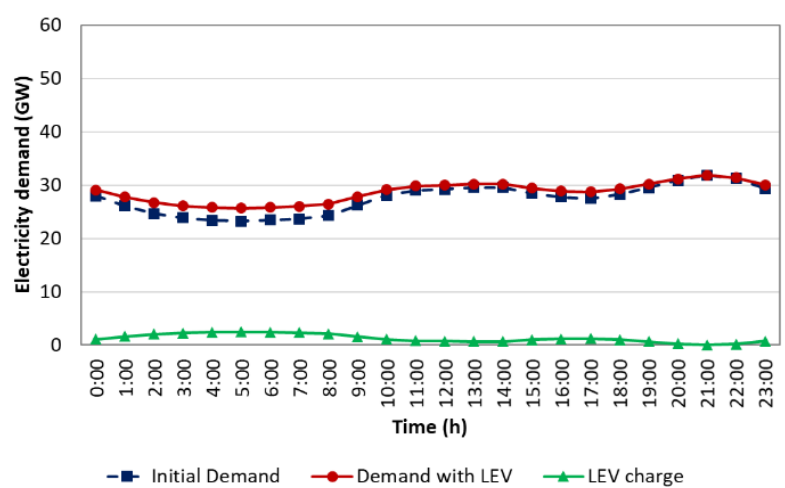

LEV penetration $=50 \%$

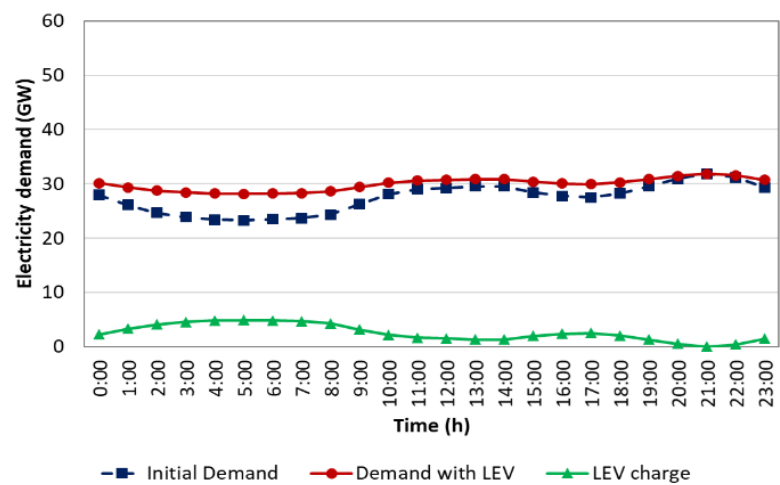

LEV penetration $=75 \%$

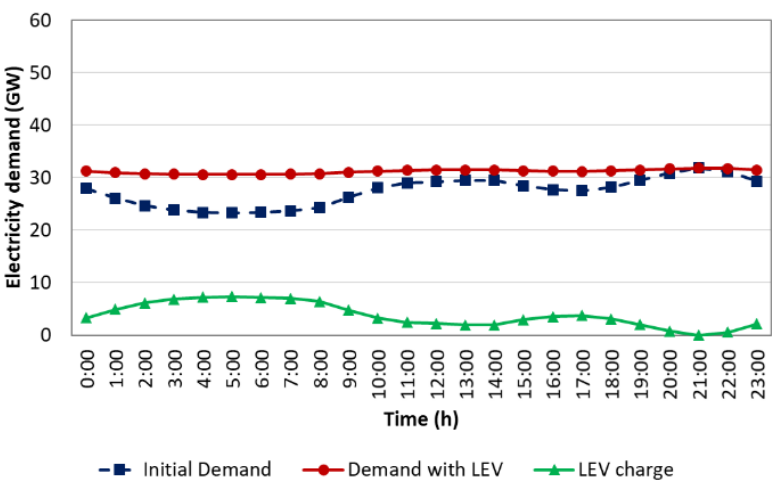

(b)

Figure 6. Total demand profiles in the low growth scenario. (a) Working day. (b) Non-working day. 

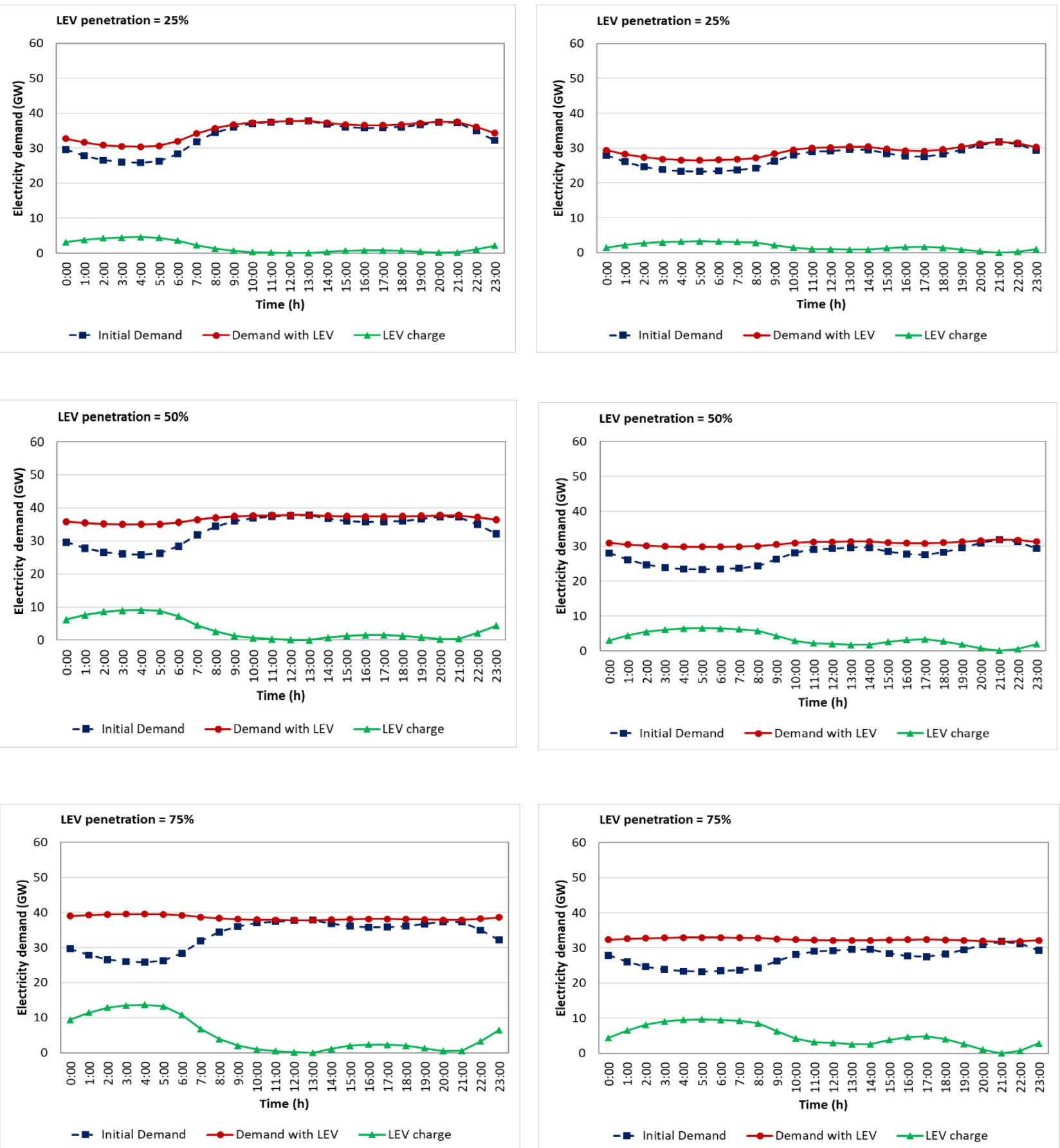

(a)

(b)

Figure 7. Total demand profiles in the medium growth scenario. (a) Working day. (b) Non-working day. 

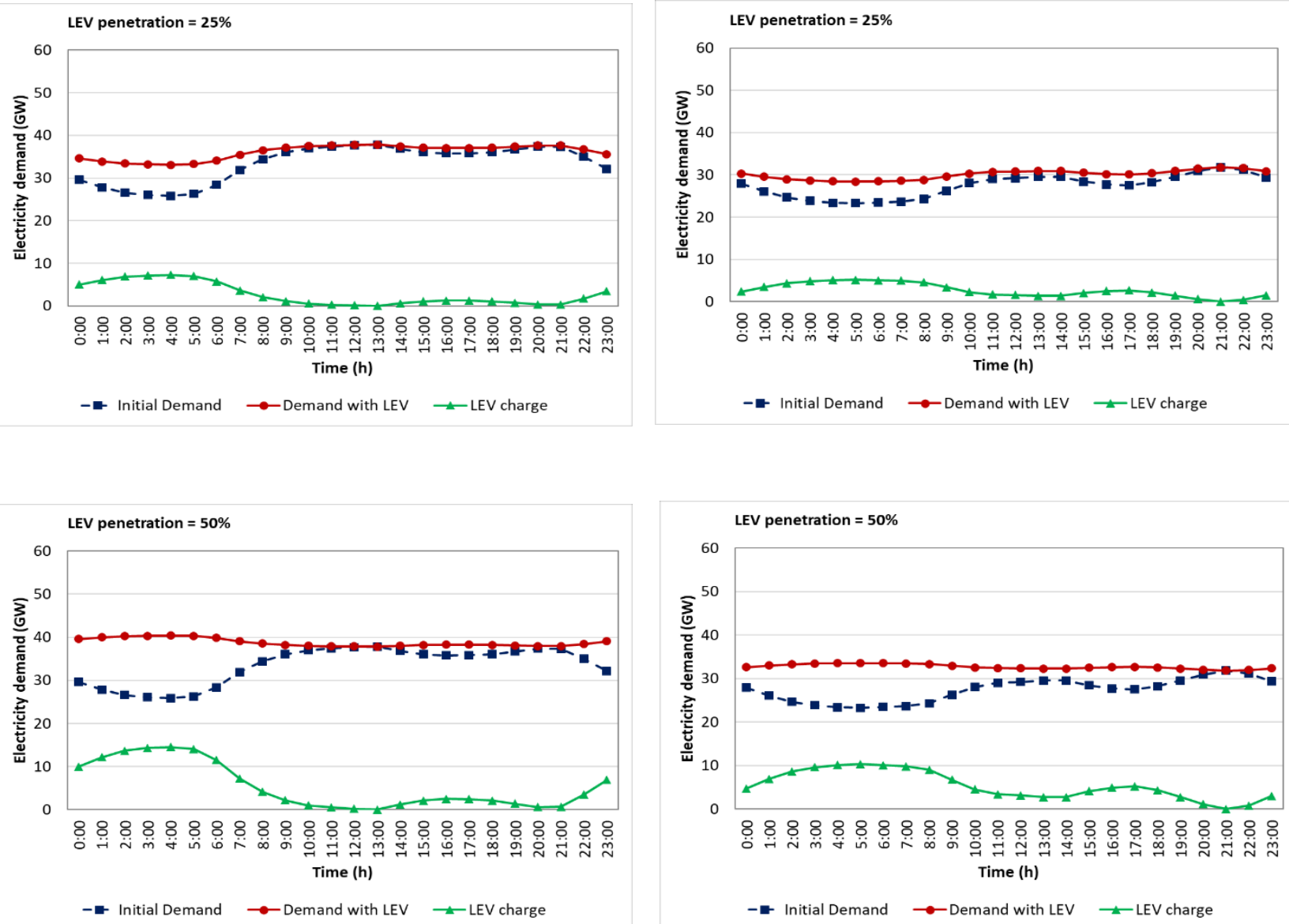

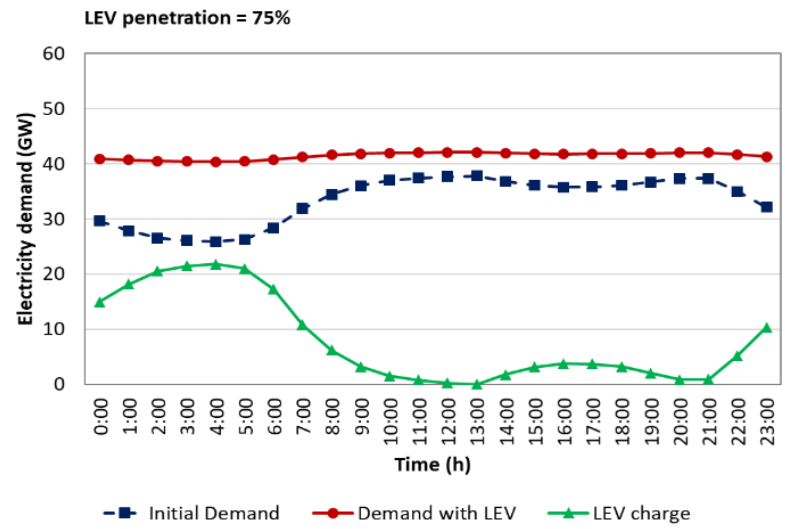

(a)

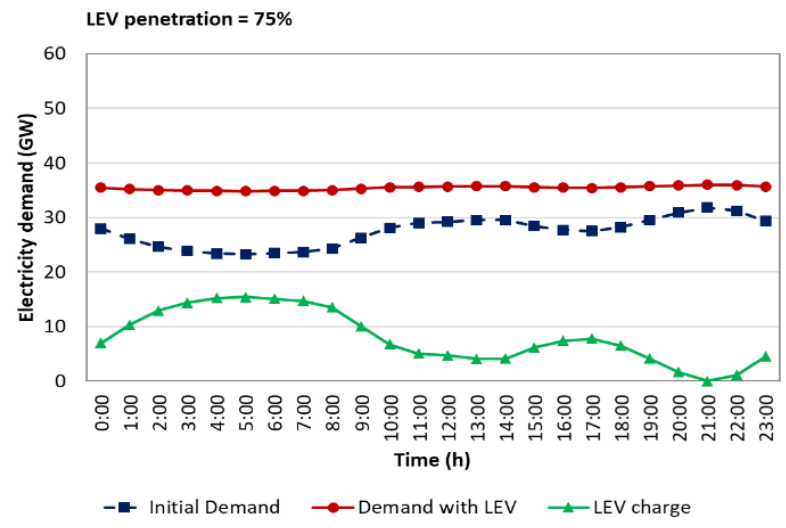

(b)

Figure 8. Total demand profiles in the high growth scenario. (a) Working day. (b) Non-working day.

To quantify the effect of the LEV penetration with this controlled recharging method, the flat parameter for each profile is calculated by using eq. 7 and, together with the maximum demand power, the obtained values are compared with the corresponding ones for the initial profile. Results are presented in Table 4 for working days where it can be deduced that in all the scenarios a flatter profile 
than the initial one is obtained. The maximum value of the electricity demand is preserved for most of the cases and only in the higher penetration for the medium growth and in the intermediate and high penetration for the high growth scenario is necessary an increase of power in the electricity system. Similar behavior is obtained for the case of non-working days as table 5 shows.

Table 4. Profile flattening of the demand profile for working days.

\begin{tabular}{|c|c|c|c|c|c|}
\hline \multicolumn{4}{|c|}{ Initial demand curve } & \multicolumn{2}{|c|}{ Total demand curve } \\
\hline Scenario & $\begin{array}{l}\text { Maximum } \\
(\mathrm{GW})\end{array}$ & Flat factor & LEV fraction (\%) & $\begin{array}{l}\text { Maximum } \\
(\mathrm{GW})\end{array}$ & Flat factor \\
\hline & & & 25 & 37,8 & 0,917 \\
\hline \multirow[t]{2}{*}{ Low } & 37,8 & 0,883 & 50 & 37,8 & 0,950 \\
\hline & & & 75 & 37,8 & 0,984 \\
\hline \multirow{3}{*}{ Medium } & & & 25 & 37,8 & 0,928 \\
\hline & 37,8 & 0,883 & 50 & 37,8 & 0,972 \\
\hline & & & 75 & 39,5 & 0,973 \\
\hline \multirow{3}{*}{ High } & & & 25 & 37,8 & 0,954 \\
\hline & 37,8 & 0,883 & 50 & 40,4 & 0,960 \\
\hline & & & 75 & 42,1 & 0,985 \\
\hline
\end{tabular}

Table 5. Profile flattening of the demand profile for non-working days

\begin{tabular}{|c|c|c|c|c|c|}
\hline \multicolumn{4}{|c|}{ Initial demand curve } & \multicolumn{2}{|c|}{ Total demand curve } \\
\hline Scenario & $\begin{array}{l}\text { Maximum } \\
\text { (GW) }\end{array}$ & Flat factor & LEV fraction (\%) & $\begin{array}{l}\text { Maximum } \\
\text { (GW) }\end{array}$ & Flat factor \\
\hline & & & 25 & 31,8 & 0,900 \\
\hline \multirow[t]{2}{*}{ Low } & 31,8 & 0,860 & 50 & 31,8 & 0,940 \\
\hline & & & 75 & 31,8 & 0,980 \\
\hline \multirow{3}{*}{ Medium } & & & 25 & 31,8 & 0,913 \\
\hline & 31,8 & 0,860 & 50 & 31,8 & 0,966 \\
\hline & & & 75 & 32,9 & 0,983 \\
\hline \multirow{3}{*}{ High } & & & 25 & 31,8 & 0,944 \\
\hline & 31,8 & 0,860 & 50 & 33,5 & 0,975 \\
\hline & & & 75 & 36,0 & 0,983 \\
\hline
\end{tabular}

\subsection{LEV recharging strategies}

Different studies boosted by the Spanish Government have been carried out in relation to LEV recharging strategies (home, electrical stations and public buildings). Based on these studies (AECC., 2018; Eurostat, 2018; DGT, 2019), the daily recharging probability profiles for each of them are deduced (Figure 9), as well as the contribution of each option to the total LEV demand (Figures 10 to 12). 


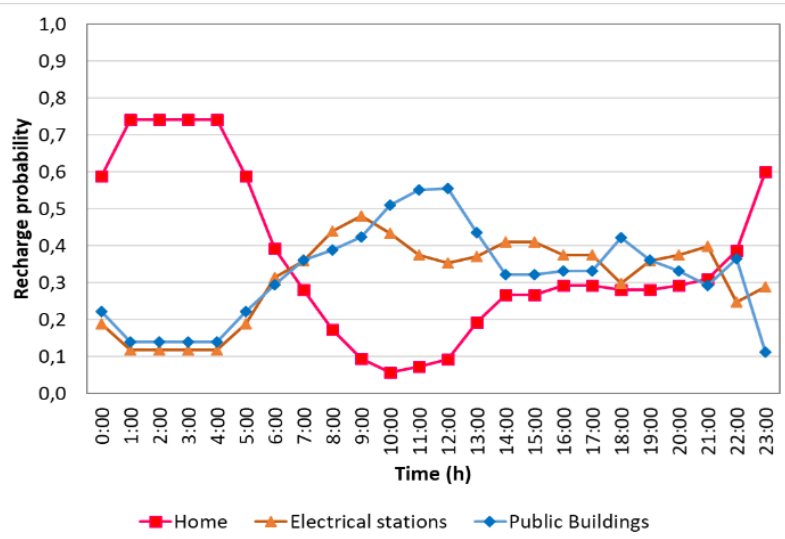

(a)

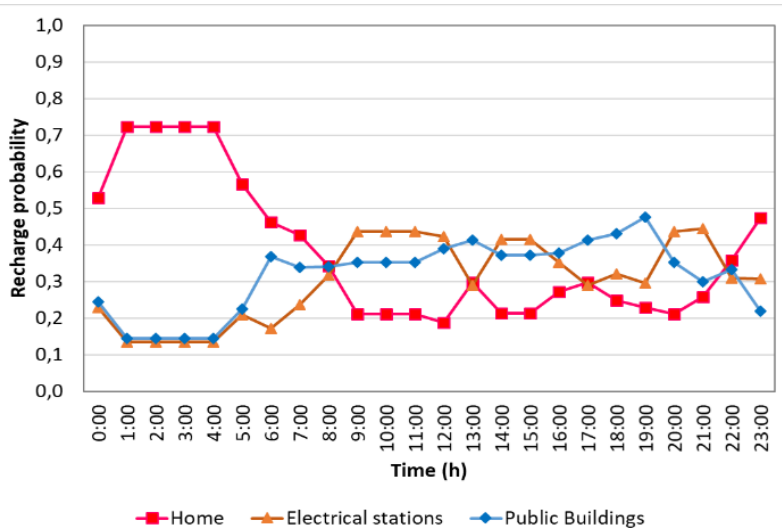

(b)

Figure 9. Daily recharging probability profiles. (a) Working day. (b) Non-working day. 

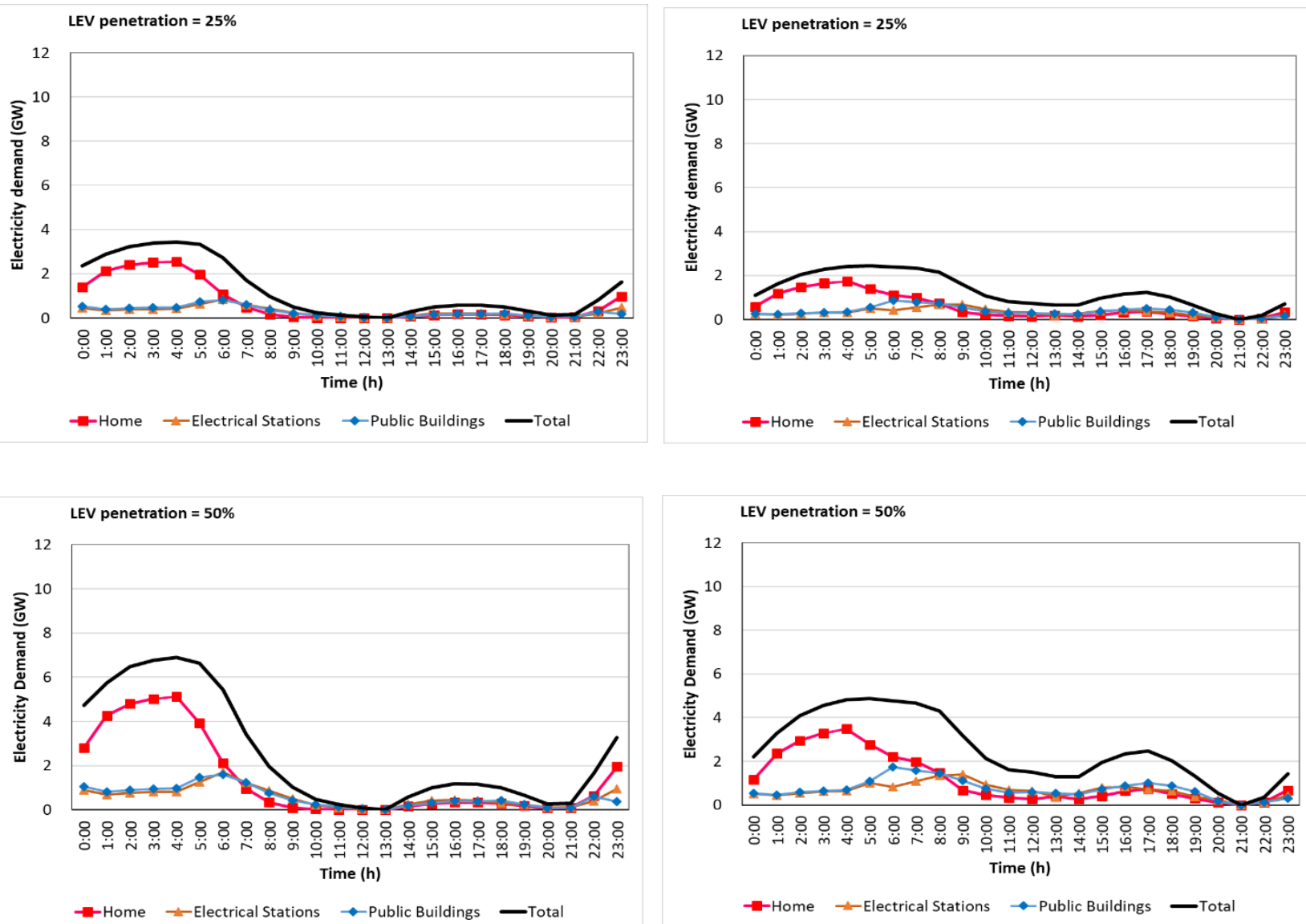

LEV penetration $=75 \%$
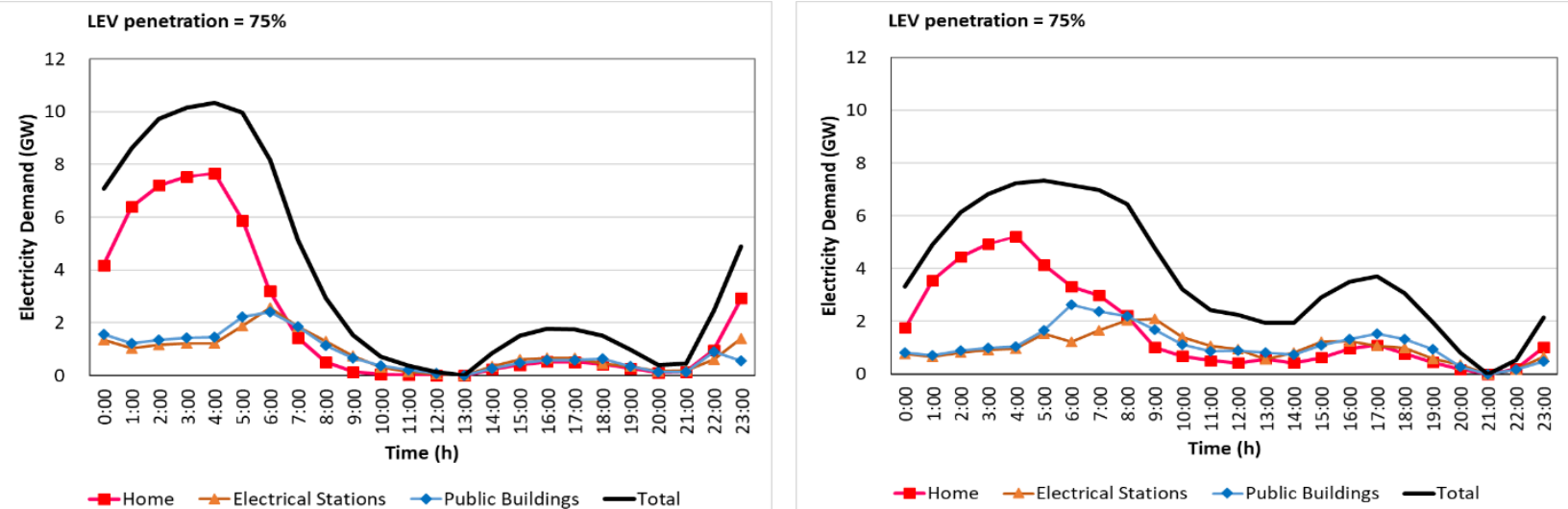

(a)

(b)

Figure 10. Electricity contributions to LEV demand for low growth scenario. (a) Working day. (b) Non-working day. 

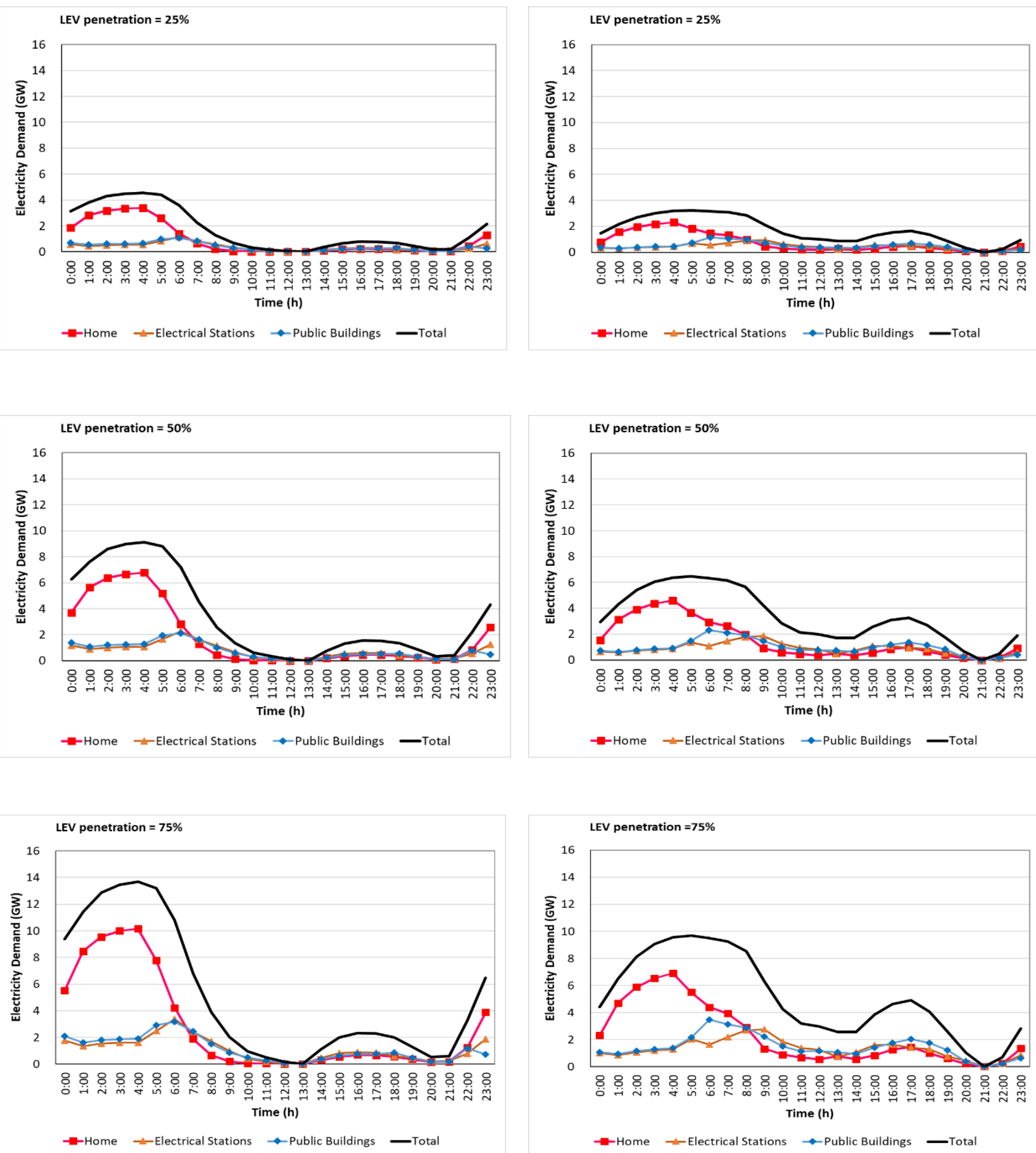

(a)

(b)

Figure 11. Electricity contributions to LEV demand for medium growth scenario. (a) Working day. (b) Non-working day. 

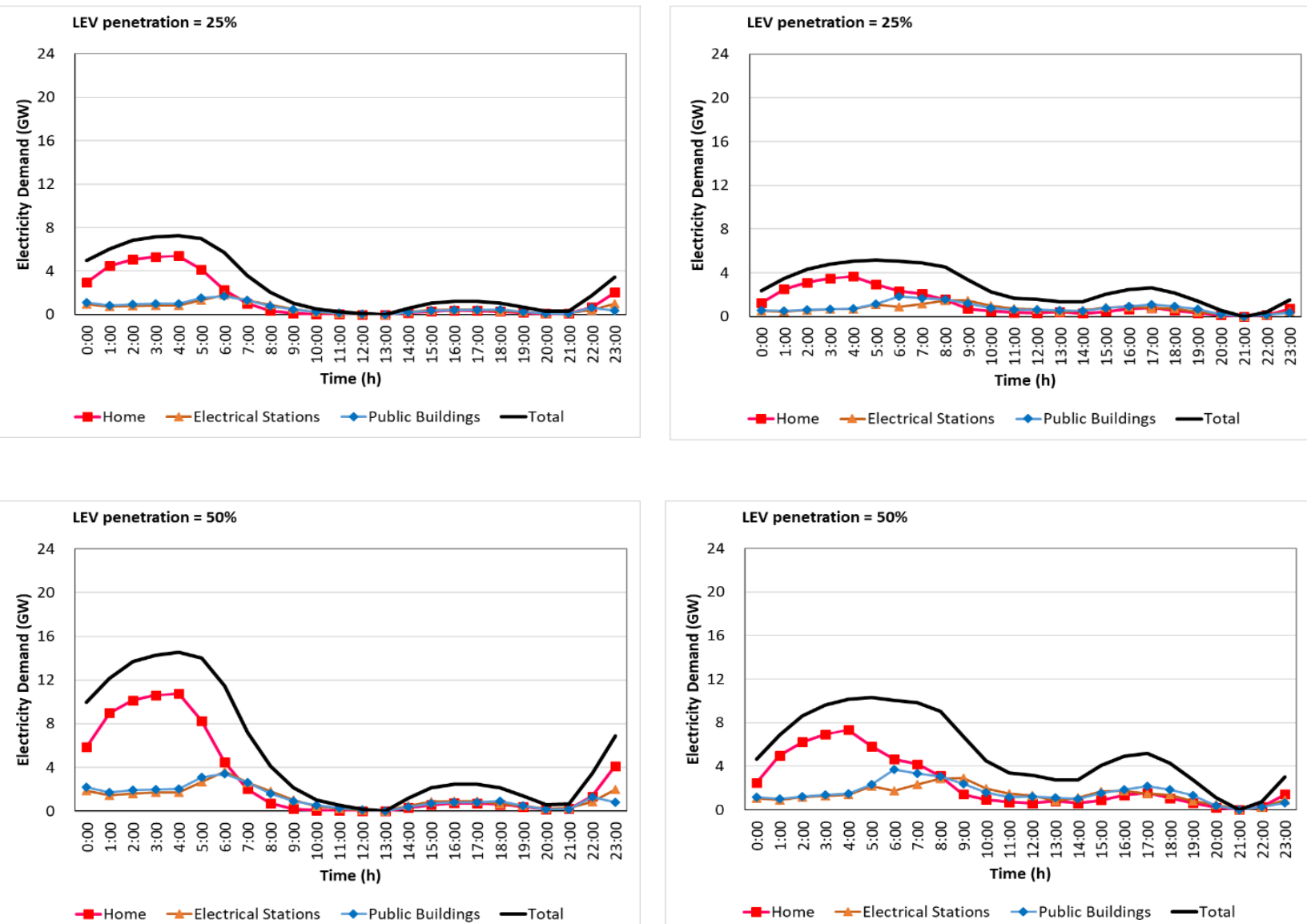

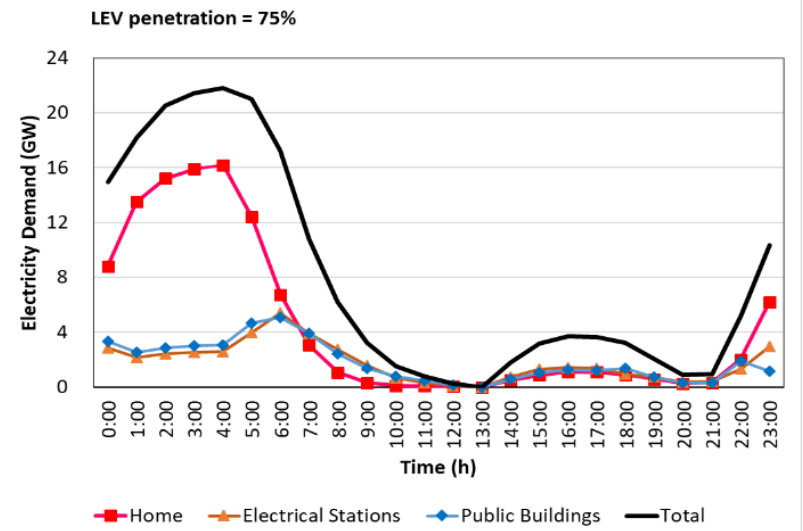

(a)

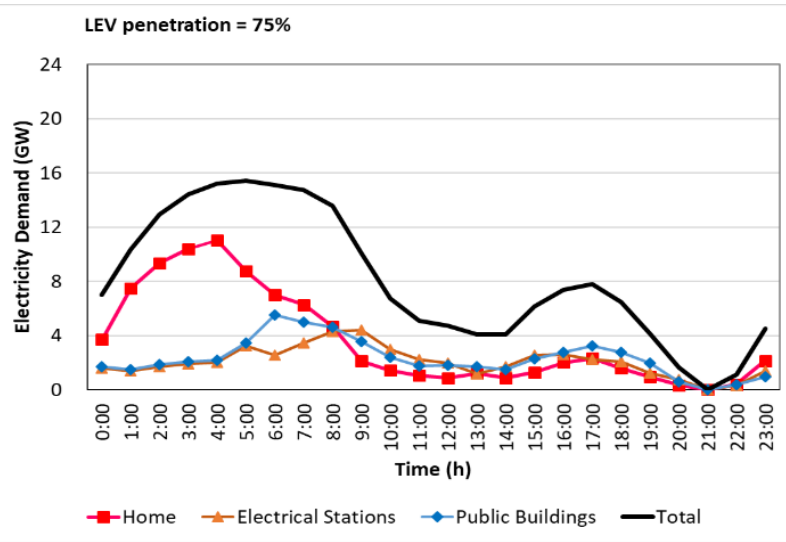

(b)

Figure 12. Electricity contributions to LEV demand for high growth scenario. (a) Working day. (b) Non-working day.

For the low and medium growth of LEV, the recharge is mainly concentrated in the night hours by using the home option and no increase in the peak value of the total electricity demand is required. When this growth increases, it is also possible to obtain a flat profile after several iterations of the method, where an increase in the peak value is given. Moreover, the contribution of every recharge option remains constant compared to the other scenarios. Numerical results for the different 
contributions are detailed in table 6 and relative contributions to the total recharge from the different options are presented in figure 13.

Table 6. Power and energy requirements for the different recharge options in working/non-working days

\begin{tabular}{cccccccc}
\hline & \multicolumn{8}{c}{$\begin{array}{c}\text { Home } \\
\text { (Working/Non working day) }\end{array}$} & $\begin{array}{c}\text { Electrical stations } \\
\text { Working/Non working day) }\end{array}$ & $\begin{array}{c}\text { Public buildings } \\
\text { (Working/Non working day) }\end{array}$ \\
\hline Scenario & $\begin{array}{c}\text { LEV fraction } \\
\text { (\%) }\end{array}$ & $\begin{array}{c}\text { Max Power } \\
\text { (GW) }\end{array}$ & $\begin{array}{c}\text { Total Energy } \\
\text { (GWh) }\end{array}$ & $\begin{array}{c}\text { Max Power } \\
\text { (GW) }\end{array}$ & $\begin{array}{c}\text { Total Energy } \\
\text { (GWh) }\end{array}$ & $\begin{array}{c}\text { Max Power } \\
\text { (GW) }\end{array}$ & $\begin{array}{c}\text { Total Energy } \\
\text { (GWh) }\end{array}$ \\
\hline \multirow{4}{*}{ Low } & 25 & $2,56 / 1,74$ & $16,91 / 13,79$ & $0,85 / 0,69$ & $6,73 / 7,88$ & $0,8 / 0,88$ & $6,84 / 8,80$ \\
& 50 & $5,11 / 3,48$ & $33,82 / 27,59$ & $1,71 / 1,39$ & $13,45 / 15,76$ & $1,60 / 1,75$ & $13,68 / 17,60$ \\
& 75 & $7,67 / 5,22$ & $50,73 / 41,38$ & $2,56 / 2,08$ & $20,18 / 23,64$ & $2,41 / 2,63$ & $20,51 / 26,40$ \\
\hline \multirow{3}{*}{ Medium } & 25 & $3,39 / 2,30$ & $22,40 / 18,27$ & $1,13 / 0,92$ & $8,91 / 10,44$ & $1,06 / 1,16$ & $9,06 / 11,66$ \\
& 50 & $6,77 / 4,61$ & $44,80 / 36,54$ & $2,26 / 1,84$ & $17,82 / 20,88$ & $2,13 / 2,32$ & $18,12 / 23,31$ \\
& 75 & $10,16 / 6,91$ & $67,20 / 54,81$ & $3,39 / 2,76$ & $26,73 / 31,32$ & $3,19 / 3,48$ & $27,18 / 34,97$ \\
\hline \multirow{3}{*}{ High } & 25 & $5,39 / 3,67$ & $35,66 / 29,09$ & $1,80 / 1,47$ & $14,19 / 16,62$ & $1,69 / 1,85$ & $14,42 / 18,56$ \\
& 50 & $10,78 / 7,34$ & $71,33 / 58,18$ & $3,60 / 2,93$ & $28,37 / 33,24$ & $3,38 / 3,70$ & $28,85 / 37,12$ \\
& 75 & $16,17 / 11,01$ & $106,99 / 87,27$ & $5,40 / 4,40$ & $42,56 / 49,87$ & $5,08 / 5,54$ & $43,27 / 55,68$ \\
\hline
\end{tabular}

\section{Conclusions}

The foreseeable high penetration of light electric vehicles (LEV) in the transport fleet of any country generates an increase in electricity demand, whose daily distribution should be optimized to avoid a substantial increment of the peak value in the existing electricity demand curve prior to the LEV penetration. This optimization would help to avoid the requirement for uploading of the actual installed power in the country. A methodology to optimize the daily distribution of this LEV electricity demand has been developed in this work. This methodology is based on the distribution of the LEV recharge by following an inverse trend when compared with the initial electricity consumption from 
the other demand sectors, apart from transport. The electricity consumption for LEV recharging is assigned to each time interval by the application to this recharge process of a distribution function, deduced from the initial demand curve by giving high priority to the valleys and maintaining as much as possible its peak value. Flattening of the total electricity demand curve is analyzed and the methodology iterates until a fixed improved value is obtained with the minimum impact of the initial peak value. The obtained LEV demand distribution is later divided among the different recharging options, such as: home, electrical stations and public buildings. The distribution probability along the day for the use of these different recharge options is deduced from reliable studies about driving patterns. In this way, an optimal scenario for recharge is deduced and its application should be addressed from the development of tariff structures and social campaigns.

This methodology has been applied to the case of Spain by the year 2030 assuming three different scenarios for the growth of the light vehicle fleet, that to say: cars and motorcycles, with a low, medium and high growth, respectively. For each of these scenarios, three different levels of penetration for the electric vehicles were considered: $25 \%, 50 \%$ and $75 \%$ of the total fleet. Considering the different driving behavior and electricity consumption for working and non-working days, two different initial electricity demand profiles were used, deduced from the database of official organizations, and extrapolated to 2030. Results from the methodology indicate an improvement in the profile flattening up to reach 0,972 , maintaining the peak value in the initial value of $37,8 \mathrm{GW}$. Only in the case of the medium growth scenario with $75 \%$ penetration and the high growth with $50 \%$ and $75 \%$ LEV penetrations was necessary to increase the peak value in a $5 \%, 7 \%$ and $11.4 \%$, respectively, but with high flattening in all of them, higher than 0,95 , so the peak value was maintained almost all the time along the day. The allocation of the recharge between the different systems: home, electrical stations and public buildings, is dominated by the home option in all the scenarios, with a share in the order of $50 \%$ of the total demand, concentrated in the night hours.

This study has verified that it is possible a high penetration of LEV in the fleet of Spain by 2030 without increasing peak load, making use of the temporal valleys and optimally rescheduling the electricity demand increase among the different recharging options. Governments should play a key role when applying this methodology. Adequate policies should be carried out in order to ensure the installation of the required recharging points of any of the options, different taxes of recharging depending on the hour, subsidies for recharging during nights at home, etc. Future research will explore how these incentives would affect the expected recharging contributions. Moreover, future works will also study how the electricity demand increase could be covered with renewable energy sources, with the support of the grid or just in island configuration. Additionally, the methodology has been oriented to the search for flat profiles, but it could be applied to other requirements on the profile shape, such as to obtain the maximum exploitation of the generation profiles coming from renewable sources, such as solar photovoltaic.

\section{Acknowledgment}

One of the authors was supported by the Generalitat Valenciana under the grant ACIF/2018/106. 


\section{References}

Adnan, N. et al. (2017) 'A market modeling review study on predicting Malaysian consumer behavior towards widespread adoption of PHEV/EV', Environmental Science and Pollution Research. Springer Verlag, 24(22), pp. 17955-17975. doi: 10.1007/s11356-017-9153-8.

AECC. (2018). Available at: http://www.aedecc.com/enlaces-de-interes/informacionestadistica/ (Accessed: 5 August 2019).

Ahmadi, L. et al. (2012) 'Impact of PHEVs Penetration on Ontario's Electricity Grid and Environmental Considerations', Energies, 5(12), pp. 5019-5037. doi: 10.3390/en5125019.

Akitt, J. W. (2018) 'Some observations on the greenhouse effect at the Earth's surface', Spectrochimica Acta Part A: Molecular and Biomolecular Spectroscopy. Elsevier, 188, pp. 127-134. doi: 10.1016/J.SAA.2017.06.051.

Al-Alawi, B. M. and Bradley, T. H. (2013) 'Review of hybrid, plug-in hybrid, and electric vehicle market modeling Studies', Renewable and Sustainable Energy Reviews, 21, pp. 190-203. doi: 10.1016/j.rser.2012.12.048.

Alhazmi, Y. A., Mostafa, H. A. and Salama, M. M. A. (2017) 'Optimal allocation for electric vehicle charging stations using Trip Success Ratio', International Journal of Electrical Power \& Energy Systems, 91, pp. 101-116. doi: 10.1016/j.ijepes.2017.03.009.

Bagher Sadati, S. M. et al. (2019) 'Operational scheduling of a smart distribution system considering electric vehicles parking lot: A bi-level approach', International Journal of Electrical Power \& Energy Systems. Elsevier, 105, pp. 159-178. doi: 10.1016/J.IJEPES.2018.08.021.

Baran, R. and Legey, L. F. L. (2013) 'The introduction of electric vehicles in Brazil: Impacts on oil and electricity consumption', Technological Forecasting and Social Change. North-Holland, 80(5), pp. 907-917. doi: 10.1016/J.TECHFORE.2012.10.024.

Bjerkan, K. Y., Nørbech, T. E. and Nordtømme, M. E. (2016) 'Incentives for promoting Battery Electric Vehicle (BEV) adoption in Norway', Transportation Research Part D: Transport and Environment. Pergamon, 43, pp. 169-180. doi: 10.1016/J.TRD.2015.12.002.

Canals Casals, L. et al. (2016) 'Sustainability analysis of the electric vehicle use in Europe for CO2 emissions reduction', Journal of Cleaner Production. Elsevier, 127, pp. 425-437. doi: 10.1016/J.JCLEPRO.2016.03.120.

Ceballos Delgado, J. E., Caicedo Bravo, E. and Ospina Arango, S. (2016) 'A Methodological Proposal to Measure the Impact of Electric Vehicles on the Electric Grid', Ingeniería. Universidad Distrital Francisco José de Caldas, 21(2), pp. 154-175. doi: 10.14483/udistrital.jour.reving.2016.2.a03.

Clairand, J.-M., Rodríguez-García, J. and Álvarez-Bel, C. (2018) 'Electric Vehicle Charging Strategy for Isolated Systems with High Penetration of Renewable Generation', Energies, 11(11), p. 3188. doi: 10.3390/en11113188.

Dang, Q. (2018) 'Electric Vehicle (EV) Charging Management and Relieve Impacts in Grids', 9th IEEE International Symposium on Power Electronics for Distributed Generation Systems. doi: 10.1109/PEDG.2018.8447802.

Dang, Q. and Huo, Y. (2018) 'Modeling EV fleet Load in Distribution Grids: A Data-Driven Approach', in 2018 IEEE Transportation Electrification Conference and Expo (ITEC). IEEE, pp. 720-724. doi: 10.1109/ITEC.2018.8450195.

Danté, A. W. et al. (2019) ‘Online modeling and identification of plug-in electric vehicles sharing 
a residential station', International Journal of Electrical Power \& Energy Systems. Elsevier, 108, pp. 162-176. doi: 10.1016/J.IJEPES.2018.12.024.

Deb, S. et al. (2018) 'Impact of Electric Vehicle Charging Station Load on Distribution Network', Energies, 11(1), p. 178. doi: 10.3390/en11010178.

Desai, R. R., Chen, R. B. and Armington, W. (2018) 'A Pattern Analysis of Daily Electric Vehicle Charging Profiles: Operational Efficiency and Environmental Impacts', Journal of Advanced Transportation, 2018, pp. 1-15. doi: 10.1155/2018/6930932.

DGT (2017) Vehicle fleet historical data base. Available at: http://www.dgt.es/es/seguridadvial/estadisticas-e-indicadores/parque-vehiculos/series-historicas/ (Accessed: 2 January 2019).

DGT (2019) Traffic information. Available at: http://infocar.dgt.es/etraffic/ (Accessed: 19 September 2019).

Dijk, M., Orsato, R. J. and Kemp, R. (2013) 'The emergence of an electric mobility trajectory', Energy Policy. Elsevier, 52, pp. 135-145. doi: 10.1016/J.ENPOL.2012.04.024.

Eurostat (2018) Database - Eurostat. Available at: https://ec.europa.eu/eurostat/web/Ifs/data/database (Accessed: 2 August 2019).

Galiveeti, H. R., Goswami, A. K. and Dev Choudhury, N. B. (2018) 'Impact of plug-in electric vehicles and distributed generation on reliability of distribution systems', Engineering Science and Technology, an International Journal. Elsevier, 21(1), pp. 50-59. doi: 10.1016/J.JESTCH.2018.01.005.

Gong, L. et al. (2018) 'Spatial and Temporal Optimization Strategy for Plug-In Electric Vehicle Charging to Mitigate Impacts on Distribution Network', Energies, 11(6), p. 1373. doi: 10.3390/en11061373.

Hasan, M. A. et al. (2019) 'Emissions from the road transport sector of New Zealand: key drivers and challenges', Environmental Science and Pollution Research. Springer Verlag, 26(23), pp. 2393723957. doi: 10.1007/s11356-019-05734-6.

IDAE (2012) Technological electric mobility map. Available at: http://www.idae.es/uploads/documentos/documentos_Movilidad_Electrica_ACC_c603f868.pdf (Accessed: 7 January 2019).

INE (2018) Average distance covered by vehicles fleet. Available at: http://www.ine.es/jaxi/Tabla.htm?path=/t25/p500/2008/p10/I0/\&file=10020.px\&L=0 (Accessed: 30 December 2018).

Limmer, S. and Rodemann, T. (2019) 'Peak load reduction through dynamic pricing for electric vehicle charging', International Journal of Electrical Power \& Energy Systems. Elsevier, 113, pp. 117128. doi: 10.1016/J.IJEPES.2019.05.031.

Liu, Z. et al. (2014) 'Day-Ahead Energy Planning with 100\% Electric Vehicle Penetration in the Nordic Region by 2050', Energies, 7(3), pp. 1733-1749. doi: 10.3390/en7031733.

López, M. A. et al. (2015) 'Demand-side management in smart grid operation considering electric vehicles load shifting and vehicle-to-grid support', International Journal of Electrical Power \& Energy Systems. Elsevier, 64, pp. 689-698. doi: 10.1016/J.IJEPES.2014.07.065.

Luca de Tena, D. and Pregger, T. (2018) 'Impact of electric vehicles on a future renewable energy-based power system in Europe with a focus on Germany', International Journal of Energy Research, 42(8), pp. 2670-2685. doi: 10.1002/er.4056.

Mao, D., Gao, Z. and Wang, J. (2019) 'An integrated algorithm for evaluating plug-in electric 
vehicle's impact on the state of power grid assets', International Journal of Electrical Power \& Energy Systems. Elsevier, 105, pp. 793-802. doi: 10.1016/J.IJEPES.2018.09.028.

Martínez-Lao, J. et al. (2017) Electric vehicles in Spain: An overview of charging systems, Renewable and Sustainable Energy Reviews. Pergamon. doi: 10.1016/J.RSER.2016.11.239.

Morrissey, P., Weldon, P. and O'Mahony, M. (2016) 'Future standard and fast charging infrastructure planning: An analysis of electric vehicle charging behaviour', Energy Policy. Elsevier, 89, pp. 257-270. doi: 10.1016/J.ENPOL.2015.12.001.

Ortega-Vazquez, M. A., Bouffard, F. and Silva, V. (2013) 'Electric Vehicle Aggregator/System Operator Coordination for Charging Scheduling and Services Procurement', IEEE Transactions on Power Systems, 28(2), pp. 1806-1815. doi: 10.1109/TPWRS.2012.2221750.

PNIEC (2019) Spanish climate change draft law. Available at: https://www.miteco.gob.es/es/prensa/ultimas-noticias/el-consejo-de-ministros-da-luz-verde-alanteproyecto-de-ley-de-cambio-climático-/tcm:30-487294 (Accessed: 12 April 2019).

REE (2017a) Electrical demand, energy generation structure and CO2 emissions. Available at: https://demanda.ree.es/visiona/peninsula/demanda/total/2018-10-16 (Accessed: 27 December 2018).

REE (2017b) Historical Data Base. Available at: https://www.ree.es/es/estadisticas-delsistema-electrico-espanol/series-estadisticas/series-estadisticas-nacionales (Accessed: 26 December 2018).

REE (2018) Electric mobility guide for local entities. Available at: https://www.ree.es/sites/default/files/downloadable/Guia_movilidad_electrica_para_entidades_loc ales.pdf (Accessed: 31 July 2019).

Su, J., Lie, T. T. and Zamora, R. (2019) 'Modelling of large-scale electric vehicles charging demand: A New Zealand case study', Electric Power Systems Research. Elsevier, 167, pp. 171-182. doi: 10.1016/J.EPSR.2018.10.030.

Sundstrom, O. and Binding, C. (2012) 'Flexible Charging Optimization for Electric Vehicles Considering Distribution Grid Constraints', IEEE Transactions on Smart Grid, 3(1), pp. 26-37. doi: 10.1109/TSG.2011.2168431.

Teixeira, A. C. R. and Sodré, J. R. (2018) 'Impacts of replacement of engine powered vehicles by electric vehicles on energy consumption and $\mathrm{CO} 2$ emissions', Transportation Research Part D: Transport and Environment. Pergamon, 59, pp. 375-384. doi: 10.1016/J.TRD.2018.01.004.

Tietge, U., Díaz, S., et al. (2016) 'From laboratory to road: A 2016 update of official and "realworld" fuel consumption and $\mathrm{CO} 2$ values for passenger cars in Europe', The International Council on Clean Transportation. Available at: https://theicct.org/publications/laboratory-road-2016-update.

Tietge, U., Mock, P., et al. (2016) 'Real-world fuel consumption of popular European passenger car models | International Council on Clean Transportation', The International Council on Clean Transportation. Available at: https://www.theicct.org/publications/real-world-fuel-consumptionpopular-european-passenger-car-models.

Valsera-Naranjo, E. et al. (2012) 'Probabilistic Method to Assess the Impact of Charging of Electric Vehicles on Distribution Grids', Energies. Molecular Diversity Preservation International, 5(5), pp. 1503-1531. doi: 10.3390/en5051503.

Wang, L. and Chen, B. (2019) 'Distributed control for large-scale plug-in electric vehicle charging with a consensus algorithm', International Journal of Electrical Power \& Energy Systems. 
Elsevier, 109, pp. 369-383. doi: 10.1016/J.IJEPES.2019.02.020.

Wang, X., Wei, X. and Dai, H. (2019) 'Estimation of state of health of lithium-ion batteries based on charge transfer resistance considering different temperature and state of charge', Journal of Energy Storage. Elsevier Ltd, 21, pp. 618-631. doi: 10.1016/j.est.2018.11.020.

Wang, Y. and Infield, D. (2018) 'Markov Chain Monte Carlo simulation of electric vehicle use for network integration studies', International Journal of Electrical Power \& Energy Systems. Elsevier, 99, pp. 85-94. doi: 10.1016/J.IJEPES.2018.01.008.

Zhang, K. et al. (2019) 'Parameter Identification and State of Charge Estimation of NMC Cells Based on Improved Ant Lion Optimizer', Mathematical Problems in Engineering, pp. 1-18. doi: 10.1155/2019/4961045.

Zhao, X., Ma, J., et al. (2018) 'Developing an electric vehicle urban driving cycle to study differences in energy consumption', Environmental Science and Pollution Research. Springer Verlag, 26(14), pp. 13839-13853. doi: 10.1007/s11356-018-3541-6.

Zhao, X., Yu, Q., et al. (2018) 'Development of a Representative EV Urban Driving Cycle Based on a k- Means and SVM Hybrid Clustering Algorithm', Journal of Advanced Transportation, pp. 1-18. doi: 10.1155/2018/1890753. 